\title{
DIE INVLOED VAN DIE MENS OP DIE PLANTEGEMEENSKAPPE VAN DIE NASIONALE KRUGERWILDTUIN
}

Die natuurlike gemeenskap wat bestaan uit sowel plante as diere en wat in 'n groot mate deur anorganiese ongewingsfaktore beheer word, neig, hoewel dit selde bereik word, steeds tot 'n skommelende ewewig tussen anorganiese omgewingsfaktore en die biotiese komponente van die gemeenskap. Onder natuurlike toestande waar die ,beskaafde mens" 'n minimale of geen invloed uitgeoefen het nie, het die plant- en diergemeenskappe hand aan hand ontwikkel en by mekaar ingepas om ' $\mathrm{n}$ min of meer stabiele ewewig daar te stel. Die primitiewe mens het, net soos die dier, 'n komponent gevorm van hierdie geheel en daarby ingepas. Met die verskyning van die leskaafde mens op die toneel verander toestande heeltemal, want dan tree 'n allesoorheersende agens op die voorgrond wat deur sy praktyke die oorspronklike ekosisteem vernietig en 'n nuwe daarstel waarvoor 'n nuwe ewewig uitgewerk moet word waarby hy kan inpas. Deur sy toenemende beheer oor die natuur het die mens 'n unieke vernietigingsagens van die oorspronklike ekosisteem geword (vergelyk Tansley, 1939, b. 228).

Ook in die Krugerwildtuin is hierdie invloed van die mens op die natuurlike gemeenskappe maar in besonder op die natuurlike plantgemeenskappe waarneembaar.

\section{Die invloed van naturelleplakkers:}

Sedert sy stigting (1926) is daar nog heelwat naturelleplakkers in die Wildtuin woonagtig. In 1953 het in die Pretoriuskopgebied alleen 29 gesinne gewoon, wat ongeveer 300 morge grond bewerk het. Omdat die Bantoe verskuiwende landbou (shifting cultivation) beoefen, is sy invloed op natuur- 


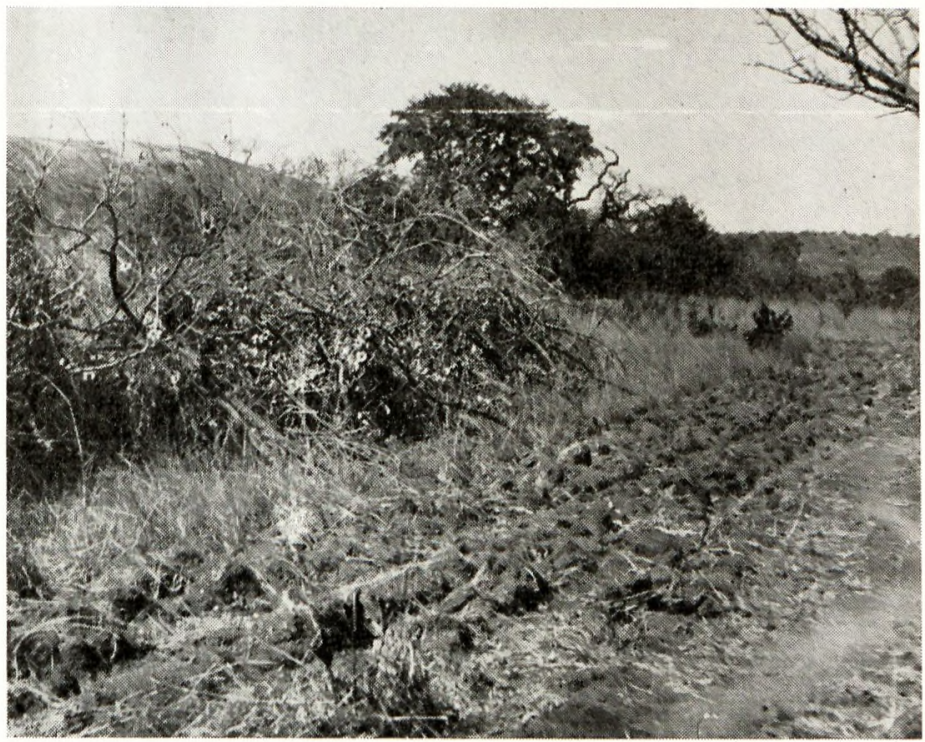

FIGUUR 1.

Takheining van kiaat (Pterocarpus angolencis) om plakkerlande in die Numbi-gebied naby Pretoriuskop.

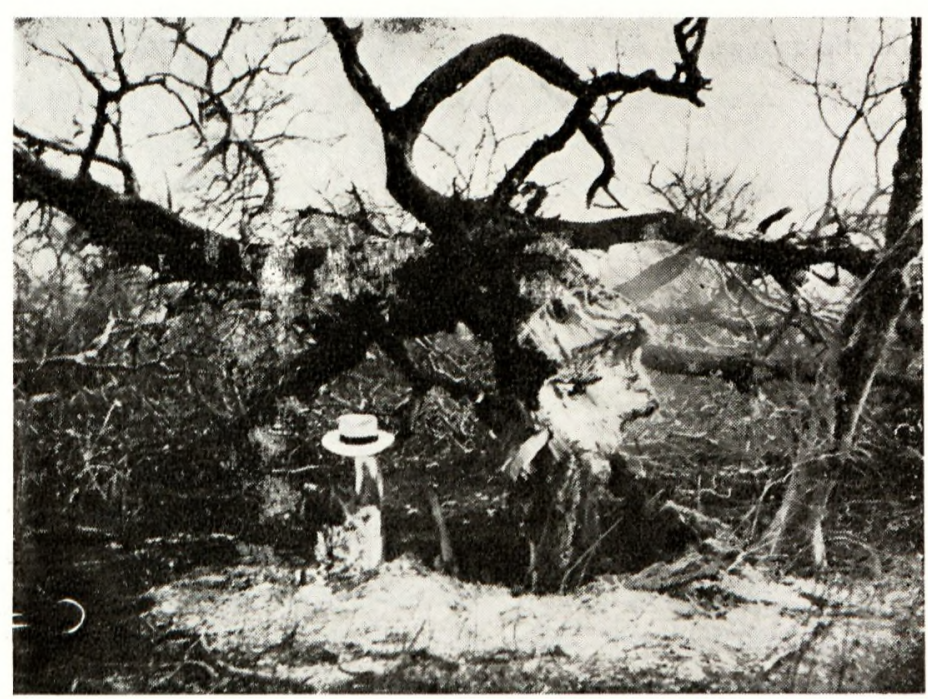

FIGUUR 2

Acacia nigrescens: Hoogte 30', stamdeursnee by grond 2'. 


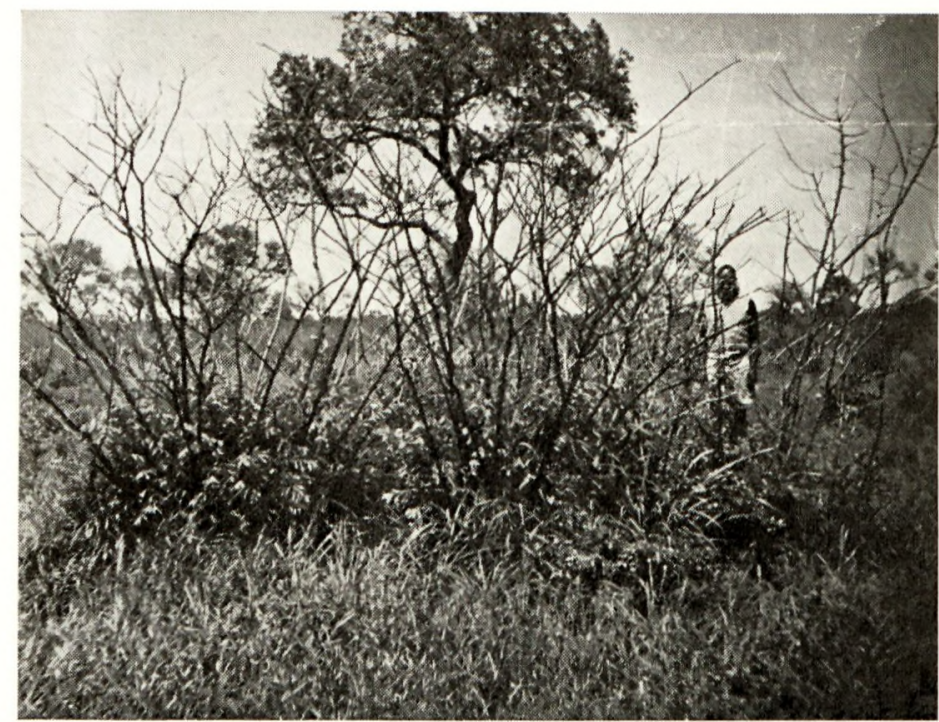

FIGUUR 3.

Struikgewas wat in Julie gebrand is en weer in November sterk boskasiegroei vorm. Hierdie struikgroep bestaan uit Grewia kwebensis, Dichrostachys cinerea subsp. glomerata, Commiphora betschuanica en Ehretia amoena. Al die struike is tot die grond toe teruggebrand maar het weer uitgeloop. 
like plantgemeenskappe aansienlik. Met die uitsondering van sekere groot bome wat eetbare vrugte dra of wat skaduwee verskaf, word die plantegroei voor die voet uitgeroei vir die aanlê van nuwe lande. Hierdie lande word dan 'n aantal jare lank bewerk, en sodra die produksie afneem, word hulle net so gelaat en nuwe lande word aangelê. Om die wild uit die gesaaides te hou, word die lande in die Wildtuin omhein met takke wat in die omgewing gekap word (Fig. 1). Op dié manier word die bos in die verloop van tyd oor taamlik groot gebiede baie uitgedun, want dit neem jare voordat die plantegroei van sulke oulande weer 'n stabiele stadium (die klimaks) leereik. Volgens oorlewering was die hele langgrasgebied om Pretoriuskop vroeër deur Bantoes bewoon. Die aanwesigheid van maalklippe bevestig die geloofwaardigheid hiervan. Die onstabiele toestand van hierdie plantgemeenskap moet dan ook, soos elders aangetoon (Van der Schijff; ongep.), tot 'n baie groot mate toegeskryf word aan die naturellelandbou wat in die verlede hier beoefen was. Dit stem ooreen met Acocks (1952) se bevindings in die gebied wat deur die Matabelies bewoon was.

Tot 1939 het hierdie plakkers (sowel as veldwagters) ook nog vee aangehou, wat in die onmiddellike omgewing van hulle statte die veld aansienlik uitgetrap het. Met die uitbreek van bek- en klouseer in 1939 is daar volgens Diesel (1954) in die Wildtuin 1322 grootvee, 321 kleinvee en 6 varke doodgeskiet. Die plakkers wat tans nog in die Wildtuin aangetref word, mag elkeen net 'n paar donkies aanhou.

\section{Invloed van toerisme:}

Toeristeverkeer het sedert die stigting van die Wildtuin in 1926 steeds toegeneem (vergelyk tabel I). Dit is 'n baie welkome verskynsel wat 'n bewys is van die belangstelling in natuurbewaring, maar tegelykertyd is dit 'n onbepaalbare nuwe omgewingsfaktor wat saam met ander faktore die oorspronklike natuurlike omgewing verander. Die effek van hierdie veranderings op die bewaring van spesies en die inskakeling van hierdie nuwe komponent om 'n nuwe stabiele ekosisteem daar te stel, eis noukeurige navorsing. 
TABEL I.

Toename in getal motors en besoekers wat jaarliks die Nasionale Krugerwildtuin besoek

\begin{tabular}{|c|c|c|}
\hline Jaar & Getal voertuie & Getal besoekers \\
\hline $1927 \ldots \ldots \ldots$ & 3 & 10 \\
\hline $1928 \ldots \ldots \ldots \ldots$ & 180 & - \\
\hline 1929 & 850 & - \\
\hline $\begin{array}{llllll}1939 & \ldots & \ldots & \ldots & \ldots\end{array}$ & 8,533 & 32,603 \\
\hline 1949 & 17,019 & 66,080 \\
\hline $1959 \quad \ldots \ldots \ldots \ldots \ldots$ & 34,501 & 135,740 \\
\hline
\end{tabular}

In die Wildtuin beïnvloed toeristeverkeer die plantegroei op die volgende maniere:

\subsection{Die bou van ruskampe:}

In die verlede is kampe in wildryke dele aangelê, met die gevolg dat die weigebied en bewegings van die wild verander is.

As kampe gebou word, word plantegroei vernietig. Dieselfde gebeur daarna, as die kamp in stand gehou word.

Dekgras en timmerasie vir die hutte was in die verlede en is tans nog in 'n sekere mate uit die Wildtuin afkomstig. Ook brandhout vir kampvure word in die Wildtuin versamel.

In ruskampe word heel dikwels uitheemse plantesoorte aangeplant wat hiervandaan „ontsnap" en in die natuurlike veld versprei. Die anwesigheid van seringbome (Melia azedarach) in die Sabierivier by Skukuza is 'n voorbeeld hiervan. In die omgewing van Skukuza word ook Catharanthus roseas (Lochnera rosea) en Lantana camara wild in die veld aangetref.

\subsection{Paaie:}

Ongeveer 1500 myl toeristepaaie is in die Wildtuin oop)gekap. Afgesien hiervan is daar gedurende die toeristeseisoen gedurig 'n ophoping van stof op die plante langs diie paaie. Verder skep die afleivore gunstige toestande vir die ontwikkeling van struike en bome. 


\subsection{Veldbrande:}

Toeriste is baie dikwels regstreeks die oorsaak van veldbrande. In die verlede het by beamptes ook die neiging bestaan om die veld langs die paaie te brand, sodat wild na die jong brand gelok kon word ter wille van die toeriste.

\section{Die invloed van bestuur:}

3.1. Deur die toepassing al dan nie van roofdierkontrole word nie alleen die diergemeenskappe nie, maar ook die plantgemeenskap beïnvloed. Te veel wild lei tot oorbeweiding, terwyl te min wild lei tot onderbeweiding.

3.2. Deur die bou van damme en die oprigting van wind. pompe word nuwe gebiede beweibaar gemaak. Die dam sell nefen ook invloed op die plantegroei uit, want in nuwe damme wat gebou word, kom heelwat bome onder water en versuip.

Verder kan die onoordeelkundige voorsiening van water, soos by 'Tshokwane die geval is, lei tot veldagteruitgang en gronderosie. In hierdie gebied is daar vier waterputte binne 'n radius van ongeveer $8 \mathrm{myl}$, warvan die Orpendam standhoudend is. Die gevolg hiervan is dat die wild wat normaalwey sou trek as die Leeupan en die gat by Tshokwane opgedroog het, nou slegs verskuif van een waterpunt na 'n ander binne dieselfde weidingsgebied. Hierdie soetveld kry gevolglik nie meer in die lente en voorsomer (die groeiperiode) kans om te rus soos dit onder natuurlike toestande die geval was nie (Van der Schijff, 1959).

3.3. Daar is ten minste net soveel patrolleerpaaie oopgekap as wat daar toeristepaaie is.

\section{Die invloed van veldbrand:}

Sedert die vroegste tye was die plantegroei van die Wildtuin, net soos van die res van die bosveldstreke van Afrika, aan periodieke veldbrande onderhewig. Gedurende die drö̈ seisoen het vuur wat hoolsaaklik in die vroeë lente deur weerlig van „droë donderstorms" ontstaan het, groot areas afgebrand. Brande in die somer was volgens oorlewering en ondervinding wat in die Laeveld opgedoen is ook glad nie seldsaam nie. Die gevolg hiervan is dat 'n tipe plantegroei ontstaan het wat relatief bestand is teen vuur maar wat geen 
klimaats- of edafiese klimaks verteenwoordig nie. Hierdie semi-stabiele plantegroei wat deur vuur in stand gehou word, staan in Afrika by plantekoloë bekend as ' $n$ vuur- of pirofiele klimaks (pyrophilous climax).

Hierdie sub-klimaksplantegroei is baie onstabiel en word baie maklik deur vuur geaffekteer. Die effek van vuur op die plantgemeenskap hang af van: (a) die tipe gemeenskap) en die spesies wat daarin voorkom se relatiewe bestandheid teen vuur; (b) die tyd van die jaar waarin dit gebrand word; (c) hoe lank na mekaar die verskillende brande voorkom; (d) die tipe en intensiteit van beweiding na die brand; (e) die hoeveelheid reënval, en (f) die aard van die grond. Onder natuurlike toestande moet vuur egter aanvaar word as 'n natuurlike omgewingsfaktor wat bydra tot dic kenmerkende plantegroei van 'n bepaalde gebied.

Met die koms van die mens, en veral die blanke, het die relatiewe waarde van vuur as 'n ekologiese faktor egter aansienlik toegeneem en verander. Hierdie ,natuurlike omgewingsfaktor", wat hoofsaaklik as gevolg van weerlig toevallig hygedra liet om die plantegroei in 'n sekere stadium van suksessie (ontwikkeling) te hou, het nou 'n middel in die hand van die mens geword waardeur hy feitlik te alle tye die natuurlike plantegroei kan verander om tot 'n sekere mate aan sy behoeftes te voldoen. Die natuurlike "vuur-klimaks" moes dan ook in baie gevalle plek maak vir 'n plantgemeenskap wat aan die boer 'n beter omset verseker het; 'n soort van ,ekonomiese klimaks". Dit moet aanvaar word dat ook in die geval van die Wildtuin ongeluksvure, as gevolg van 'n digter bevolking op sy grense en 'n toename in toeristeverkeer, en doelhewuste hrand meer dikwels voorkom.

In 'n nasionale park soos die Krugerwildtuin, het alle lewende organismes teoretics dieselfde bestaansreg, met die gevolg dat baie idealiste veldhrand in dic Wildtuin sonder meer veroordeel.

Op die voor- of nadele van deeglik beplande veldbrand in die Krugerwildtuin sal nie hier ingegaan word nie. Daar sal slegs op die effek gewys word wat onbeplande en ongekontroleerde veldbrande in die verlede op die plantgemeenskappe van die Park uitgeoefen het, en tans nog uitoefen.

Jaarverslae van dic Nasionale Parkeraad lewer voldoende 
bewyse dat ongekontroleerde veldbrand in die verlede in die Wildtuin algemeen voorgekom het (Van der Schijff; ongep.). Veral die gebied op die Portugese grens, tussen die Sabie- en Olifantsrivier word dikwels afgebrand. Dele van die gebied op die grens tussen 'Nwanetzi en die Olifantsrivier is vir 5 agtereenvolgende jare afgebrand (Van der Schijff; ongep.). 1) it kan alleen agteruitgang van die natuurlike plantegroei ten gevolg hê. In die Wildtuin is daar ook veelvuldige gegewens wat daarop dui dat vuur, soos dit in die verlede voorgekom hot, die plantegroei nadelig beïnvloed het.

Vir bykans 4 jaar is gereelde waarnemings gemaak in alle veld wat in die Wildtuin afgebrand is. Verder is antekeninge gemaak en foto's geneem van groot bome wat afgehrand is asook van ou boomstompe van bome wat doodgebrand het. Hierdie gegewens saam met voorlopige waarneming wat op eksperimentele brandplotte gemaak is, het dic volgende feite alan die lig gebring:

1. In die relatief hoë reënvalgebied in die omgewing van Pretoriuskop begunstig veldbrand die vermeerdering van Hyparrhenia dissoluta en Dichrostachys cinerea subsp. nyassanc. Dit is selfs by die leek bekend dat die beste dekgras gesny word waar die veld die vorige jaar afgebrand is. Dit is gevind dat $H$. dissoluta in die stuk ,ouveld" noordoos van die Pretoriuskop-ruskamp afsterf en opgevolg word deur onkruide en later deur Panicum maximum en Setaria flabellata. In hierdie stuk veld wat vir geruime tyd nie afgebrand is nie. gaan sekelbos (Dichrostachys cinerea subsp. nyassana) ook in groot getalle dood, terwyl die struike wat nog groei geen boskasiegroei onder aan hulle stamme vorm nie.

In 'n ander stuk veld wat periodiek afgebrand word en net deur' 'n pad van die vorige geskei word, word haie min dooie sekelbosse aangetref, terwyl feitlik elke boompie boskasiegroei vertoon. Wolhuter (1950) maak ook melding van die feit dat Dichrostachys cinerea subsp. nyassana bestand is teen vuur, terwyl Walter en Volk (1954) gevalle in SuidwesAfrika vermeld waar Dichrostachys cinerea subsp. glomerata en Acacia detinens in groot getalle afsterf in veld met 'n goeic grasbedekking wat vir 'n geruime tyd teen vuur beskerm was. Dieselfde vind plaas met Dichrostachys cinerea subsp. glome. rata tussen Skukuza en Ondersabie, en volgens Bonsma (1956) 
met verskillende Acaciasoorte en sekelbos (Dichrostachys cinerea subsp. glomerata) op die Maraproefstasie en in ander dele van die Noord-Transvaalse Bosveld.

2. In die Acacia nigrescens-Sclerocarya-gemeenskap tussen Tshokwane en die Olifantsrivier is dit gevind dat Bothriochloa insculpta en Themeda triandra, maar veral eersgenoemde, deur winterbrande (Mei---Augustus) aangemoedig word. Dit stem ooreen met wat Davidson (ongep.) gevind het vir Themeda triandra in die Transwaalse suurbosveld. In die Wildtuin brand Bothriochloa insculpta baie selde skoon af. Gewoonlik brand net die blare af, terwyl die stoppels bly staan en nie veel heskadig word nie. Slegs in die laat herfs as die reën lank weggebly het, gee hierdie grassoort 'n skoonbrand. Die ander soetgrasse, soos Digitaria-spp., Brachiaria-spp. en Panicum coloratum en $P$. maximum, gee reeds vroeg in die droeë seisoen 'n skoonbrand. Hierdeur word nie alleen Bothriochlon insculpta direk bevoordeel nie maar ook indirek, omdat selektiewe beweiding hierdeur bevorder word.

Verder is in hierdie gebied talle groot knoppiesdorings (Acacia nigrescens (Fig. 2), maroelas (Sclerocarya birrea), jakkalsbessies (Diospyros mespiliformis), hardekoollome (Combretum imberbe) en bastermaroelas (Lannea kirkii) aangetref wat doodgebrand het en nie weer uitgeloop het nie. Dieselfde het in die Punda Maria-afdeling gebeur met Afzelia quanzensis en Anthocleista grandiflora en in die Shawovallei met koorsbome (Acacia xanthophloea). Daarenteen loop struike, soos Grewia-spp., Dichrostachys cinera subsp. glomerata, Securinega virosa en Cissus lonicerifolius, in die Satara-afdeling binne 'n paar dae na die brand feitlik weer 100 persent uit en vorm boskasiegroei (Fig. 3). In hierdie gebied is die geringe aantal jakkalsbessie- (Diospyros mespiliformia), maroela(Sclerocarya birrea) en hardekoolbome (Combretum imberbe) baie opvallend, en dit wil voorkom asof die natuurlike bos hesig is om verstruik te raak as gevolg van die tipe veldbrande wat daar voorkom.

3. Die huidige struikmopanie (Colophospermum mopane) op die Tsendivlakte noord van die Letabarivier is waarskynlik deels die produk van onoordeelkundige en ontydige veldbrand. Talle afgebrande mopaniestompe met 'n deursnee van 6 duim en meer, en middelmatige groot mopanieboompies kom nog 
hier en daar in hierdie plantgemeenskap voor. Op 'n foto in 1951 op die Tsendivlakte geneem kan duidelik gesien word dat die mopaniestruike regs van die pad, wat twee jaar vroeër afgebrand was, heelwat kleiner is as dié links van die pad, wat nie daardie seisoen afgebrand was nie.

Die mopaniebome is op die hasalte tussen die Letaba- en die Olifantsrivier is opvallend minder verstruik as dié op die Tsendivlakte. Dit wil voorkom asof hierdie verskynsel decls toegeskryf moet word aan die feit dat hierdic gehied baie selde afgebrand word. Ten cerste word hierdie gebied deur die twee genoemde groot riviere beskerm teen vure wat vanaf Portugees-Oos-Afrika afkomstig is, en ten tweede het dic veldwagter wat tot 1950 in hierdie gebied gestasioneer was, sover dit in sy vermoë was, geen vuur in die gebied tocgelaat nie.

4. Skaars boomsoorte, soos koorsboom (Acacia xanthoploea), jakkalsbessie (Diospyros mespiliformis), rooicssehout (Trichilia roka? ( = Temetica), Rhodesiese Mahonic (Azelia quanzensis) en boskoorshome (Anthocleista grandifolia), is haie min hestand teen vuur. Veral in die geval van koorshome (Acacia xanthophloea) rig vuur baie skade aan, want hierdie boonsoort se stam het geen beskermende kurklaag on dit teen vuur te heskerm nie. As gcoordeel moet word volgens die aantal bome wat jaarliks doodgebrand word, is vuur hesig om hierdie boomsoort in die Wildtuin uit te roci. In die Shawovallei is daar gedurende 1954, 34 groot koorshome (Acacia xanthophloea) getel tussen die Shawo-uitspanning en Shawopoort. Vanaf 1954 tot 1957, toe hierdie bome weer getel is, het vuur hulle getalle uitgedun tot 20 groot bome, terwyl die klein boompies heeltemal verstruik was en boskasiegroei gevorm het. Baie van die ou dooie bome se reste was nog sighaar op die plekke waar hulle gestaan het.

Hyphaene crinita word ook baie deur veldbrand beskadig. Tussen Punda Maria en Pafuri en in die Babalala-gebied kan heelwat swart doodgebrande stompe van 10 voet en hoër van hierdie plantsoort gesien word. Teenswoordig groei hierdic palmsoort in hierdie gebiede as 'n struik van "n paar voet hoog. Ook Phoenix reclinata word baie deur brand beskadig.

5. Geoordeel na die dooie boomstompe wil dit voorkom asof lappies digte bos wat in klowe in die Punda Malia- en 
Malelane-gebied aangetref word, stadig hesig is om as gevoly van droogtes en herhaaldelike veldbrande uit te sterf.

6. Nieteenstaande die algemene geloof dat wil gewoond is aan vuur en selde doodbrand, wil dit tog voorkom asol dit nie die geval is nie. Gedurende 'n veldbrand waardeur in Oktoler 1954 die grootste gedeelte van die Punda Malia-Shangoni-gebied afgebrand is, is die volgende diere of doodgebrand of moes as gevolg van brandwonde van kant gemaak word:
10 olifante
2 lecus
3 waterbokke
12 rooibokke
1 duiker
I vlakvark
3 steenbokkies
10 koedoes
1 wildebees
1 hastergemshok
1 sesselie

Totaal 45 dicre.

Hicrbenewens moes daar heclwat ander diere doodgelırand het wat nooit gevind is nie, terwyl die aantal kleinere diertjies en voëls wat omgekom het, moeilik hepaal kan word. Hierdic gegewens is des te sorgwekkender as dit vergelyk word met die aantal wilde diere wat gedurende die jaar deur stropers van kant gemaak is. Volgens dic jaarverslag van die Parkeraad is die volgende diere gedurende 1954 deur stropers van kant gemaak:

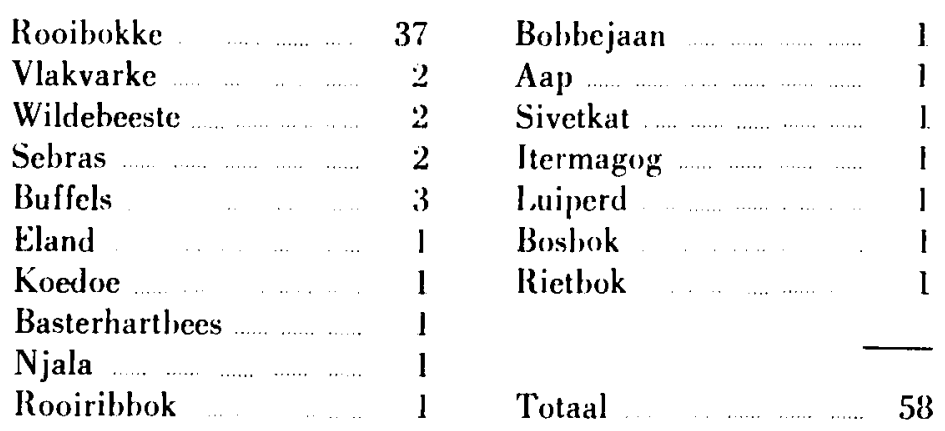


Weens die feit dat stropers moontlik weggekom het met wild wat hulle van kant gemaak het, sal hierdic getalle waarskynlik heelwat hoër moet wees, maar selfs al word dit in ag geneem, is die aantal grootwild wat as gevolg van die vuur omgekom het nog onrusharend.

7. As gevolg van ontydige veldbrand word die waterafloop verhoog en erosie bevorder. In die gevalle waar vleie afgebrand word, kan dit alleen die plantegroei en watervoorraad van so 'n vlei nadelig beïnvloed.

8. Die doeltreffendheid van veldbrand om gevestigde struikgewas uit te roei of om bosindringing te voorkom word betwyfel.

Outcurs soos Galpin (1926), Phillips (1930), Wolhuter (1950), Irvine (1943), Scolt (1951) en West (1952), is van mening dat gekontroleerde, oordeelkundige en beplande veldbrand hosindringing kan voorkom. Henkel (volgens Hutchinson, 1946), Walter en Volk (1954) en Codd (1949), daarenteen, is van mening dat veldbrand in 'n groot mate onder sekere omstandighede verantwoordclik vir bosindringing kan wees.

Navorsing hel bewys dat behalwe in die geval van Stoebe vulgaris (Smit; ongep.) en Elytropappus rhinocerotis (Bagshawe-Smith, 1937), veld wat alreeds deur gevestigde struikgewas ingeneem is, nie deur veldbrand herwin kan word nie (Irvine; ongep.); (Irvine, 194.3; Story, 1952). Na aanleidingr van resultate wat verkry is met Acacia karroo verklaar Story (1952) : „.. f far from being of value as a means of eradication of well-established scruh, fire is likely to bring about thickening of it by encouraging the growth of coppice shoots. It could, however, be used as a means of control when the area had once been cleared of older plants". Bevindings in Suidwes-Afrika deur Walter en Volk (1954) bevestig Story se waarnemings: „Noch ein anderer Faklor wird als Ursache der Verbuschung viel diskutiert: Das Aufhören der Grasbrände. Sicher spielt auch das mit eine Rolle. Bei jedem Brand werden die Büsche stark geschädigt. Es findet dabei zugleich eine gewisse $\Lambda$ uslese unter den Holzp flanzen statt. Schliesslich bleiben aber nur Büsche übrig, die die Fähigkeit besitzen, nach jedem Brand wieder rasch auszuschlagen. Ihnen kann das Feuer wenig anlaben; sie werden dann zwar nicht hoch, aber 
umso dichter. Wir hatten am Omuramba Ondengaura, nordwestlich vom Waterberg, eine Brandfläche gesehen, auf der der Busch bis zum Grunde abgebrannt war, aber dann frisch austrieb. Statt eines Kameldorns hatten sich jetzt 10 Schösslinge gebildet und ebenso hatten der Otjimbuku oder die Kerzenakazie (Acacia hebeclada) und der Warteinbisschen (Zizyphus mucronata) an Raum gewonne, so dass 2 Jahre nach dem Brande eine undurchdringliche, verbuschte Fläche entstanden war, in die kein Vieh hineingehen konnte. Der Brand hatte somit hier die Verbuschung cher begünstigt".

In die Wildtuin is ook herhaaldelik waargeneem dat gcvestigde struike wat afgebrand word, diigte boskasiegroci vorm, en dit is dus twyfelagtig of die teenswoordige manier wan veldbrand hosindringing gaan voorkom of gevestigde struikgewas gaan uitroei. In die Pretoriuskopgebied is tellings van sekelbos gemaak in veld wat afgebrand is. Op vier verskillende plekke in gebrande veld is persele van 100 voet by 200 voet afgemeet en is alle Dichrostachys cinerea subsp. nyassana struike wat hierin voorkom, getel. Sowel die aantal plante wat heeltemal doodgebrand is as dié wat tot op die grond afgebrand was maar weer uitgeloop het en die wat glad nic deur vuur beskadig is nie, is getel. Hierdie resultate word in Tahel 2 weergegee.

TABEL 2

Die invloed van vuur op Sekelbos (Dichrostachys cinerea subsp. nyassana).

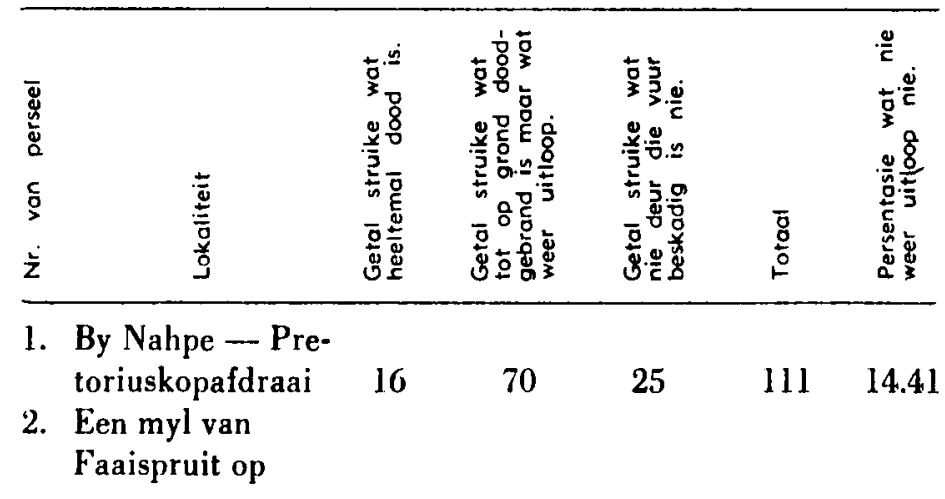




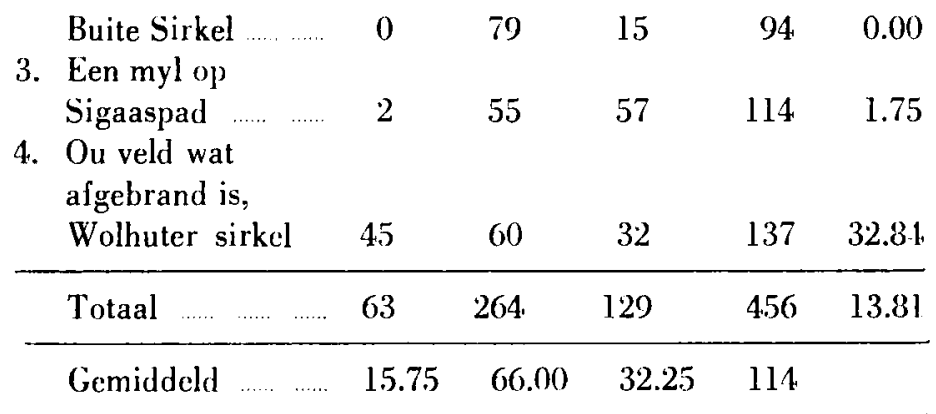

5. Ou veld nie

afgebrand,

$\begin{array}{llllll}\text { Wolhuter sirkel } & 62 & - & 86 & 148 & 41.9\end{array}$

Volgens hierdie tellings (Tabel 2) het 'n baie klein persentasie van die struike doodgebrand. Die grootste getal dooie struike het in perseel 4 voorgekom. In dié geval was die veli egter baie oud en vir 'n geruime aantal jare nie gebrand nie (Wolhuter, 1955), met die gevolg dat heelwat sekelhos (Dichrostachys cinerea subsp. nyassana) voor die brand alreeds dood was of besig was om dood te gaan.

Perseel 5 is nic afgebrand nie en word net deur 'n pad van perseel 4, geskei. In hierdie perseel (perseel 5) waarvan die gras ongeveer net so oud was as dié in persecl 4 net voordat dit afgebrand is, het 41.9 persent dooie sekelbosse (Dichrostachys cinerea subsp. nyassana) voorgekom. Hier was verder geen sekelbosstruike wat boskasiegruei gevorm het nie, terwyl die struike in die persele wat afgebrand was en weer uitgeloop het, digte boskasiegroei gevorm het.

Volgens die gegewens wat in verband met veldbrand inge. samel is, is dit duidelik dat onnatuurlike, onoordeelkundige en ontydige veldbrand in die verlede in baie gevalle die plantegroei sowel as die dierelewe nadelig beïnvloed het. Die wisselwerking tussen vuur en plantegroei is egter nic net in dic Wildtuin nie, maar in al ons bosveldstreke nog geensins duidelik nie, en navorsing in die verband is uiters noodsaaklik.

\section{OPSOMMING}

1. Ook in die Wildtuin is die invloed van die mens op dic natuurlike plantgemeenskappe waarneembaar. 
2. Naturelleplakkers het in die verlede in die Pretoriuskopgebied die natuurlike flora nadelig beïnvloed.

3. Toerisme en beheer is biotiese faktore waarvan die invloed op die natuurlike plantegroei op hierdie stadium nog nie na waarde geëvalueer kan word nie.

4. Daar is heelwat gegewens wat daarop dui dat veldbrand in die verlede gelei het tot agteruitgang in die natuurlike plantegroei in die algemeen en tot bosindringing in die besonder.

5. Navorsing en waarnemings in verband met die invloed van die mens op natuurlike biotiese gemeenskappe in die Krugerwildtuin is noodsaaklik.

Universiteit van Pretoria.

H. P. van der Schijff.

\section{LITERATUUR}

Acocks, J. P. II. (1953): Veld Types of South Africa. Bot. Survey of S. Afr., Mem. 28. Government Printers, Pretoria.

Bagshawe-Smith, L. (1937): Rhenoster Bush in the District of Albany. S. Air. J. Sci., 33; 355.

Bonsma, H. (190.5): Persoonlike Kommunikasie.

Codd, L. E. W. (1951): Trees and Shrubs of the Kruger National Park. Bot. Survey of S. Air., Mem. 26.

Darvidson, R. L. (ongep.): A Seasonal Burn Expirement in Sour Mixed Bushveld. Report. University of the Witwatersrand. Johannesburg.

Diesel, A. M. (19.54): Persoonlike Kommunikasies.

Galpin, E. E. (1926): Bolanical Survey of the Springbok Flats, Transvaal. Bot. Survey of S. Afr., Mem. 12. Government Printer, Pretoria.

llutchinson. J. (1946): $\Lambda$ Botanist in Southern Africa. P. R. Gawthorn Lid., London.

Irvine, L. O. F. (ongep.): The Major veld types of the Northern Transvaal and their grazing Management. Quinquennial report of the Towoomba Pasture Research Station.

Irvine, L. (). F. (1913): Bush Encroachment in N. Transvaal. Farming in S. Afr. 18: 725-729.

Nasionalc Parkeraad: Verskeie Jaarverslae.

Phillips, J. F. F. (1930): Fire: Its Influence on Biotic Communities and Physical Factors in South and East Africa. S. Afr. J. Scl., 27: $352-367$.

Scot1, J. D. (1951): A Contribution to the Study of the Drakensberg conservation area. Sci. Bull. 324. Dept. of Agric. U. of S. Afr.

Smil, I. B. J. (ongep.): The effect of Veld Burning on Stoebe vulgaris. B.Sc. Ilonu. Thesis, Universily of Witwatersrand, Johannesburg. 
Story, R. (1952): A Botanical Survey of the Keiskammahoek District. Bot. Survey of S. Afr. Mem. 27, Government Printer, Pretoria.

Tansley, A. G. (1939): The British Islands and their Vegetation. Cambridge University Press.

Van der Sdrijff, H. P. (ongep.): 'n Ekologiese studie van die Flora van die Nasionale Krugerwildtuin. D.Sc Proefskrif, P.U. vir C.H.O., Potchefstroom.

Van der Schijff, If. P. (1958): Inleidende verslag oor Veldbrandnavorsing in die Nasionale Krugerwildtuin, Koedoe 1, 60-92.

Van ter Schijff, H. P. (1959): Weidingsmoontlikhede en Weidingsprobleme in die Nasionale Krugerwildtuin, Koedoe 2, 96-127.

Walier, II. en Volk, O. I. (1954): Grundlagen der Weidewirtschaft in Südwestafrika. Fingen Ulmer, Stultgart.

Wesi, O. (1951): The Vegetation of Weenen County, Natal. Bot. Survey of S. Afr. Mem. 23. Government Printer, Pretoria.

West, O. (1952): Veld Gold: Plant Succession and Veld Burning considered particularly in relation to the Management of Bushveld (;razing. Nat. Veld Trust, Johannesburg.

Wolhuter, Harry, (1950): Memories of a Game-Ranger. Central News Agency, Lid., South Africa.

Wolhuter, IIenry. (1956): Persoonlike Kommunikasies. 